\title{
Tolerance in the Peer Review of
}

\section{Interdisciplinary Research in}

\section{Architectural Journal Publishing}

\section{Troiani, I}

http://hdl.handle.net/10026.1/16410

10.1080/20507828.2019.1584421

Architecture and Culture

All content in PEARL is protected by copyright law. Author manuscripts are made available in accordance with publisher policies. Please cite only the published version using the details provided on the item record or document. In the absence of an open licence (e.g. Creative Commons), permissions for further reuse of content should be sought from the publisher or author. 


\section{Architecture and Culture}

\section{Tolerance in the Peer Review of Interdisciplinary Research in Architectural Journal Publishing}

\section{Igea Troiani \& Suzanne Ewing}

To cite this article: Igea Troiani \& Suzanne Ewing (2019) Tolerance in the Peer Review of Interdisciplinary Research in Architectural Journal Publishing, Architecture and Culture, 7:1, 13-30, DOI: $10.1080 / 20507828.2019 .1584421$

To link to this article: https://doi.org/10.1080/20507828.2019.1584421

曲 Published online: 01 Jul 2019.

Submit your article to this journal $\pi$

山 Article views: 61

Q View related articles $₫$

View Crossmark data \lceil 


\section{ARCHITECTURE AND CUITURE}

Igea Troiani

Department of Architecture, Xi'an Jiaotong-Liverpool University, Suzhou, China Igea.Troiani@xjtlu.edu.cn

\section{Suzanne Ewing}

Edinburgh School of Architecture and Landscape Architecture, The University of Edinburgh, Edinburgh, UK suzanne.ewing@ed.ac.uk

Keywords: tolerance, architectural publication, interdisciplinary research, peer review, quality, editorial practice, Michel Foucault, Julia Kristeva

\section{Check for updates}

Volume $7 /$ Issue 1

March 2019

pp. $13-30$

DOI:10.1080/20507828.

2019.1584421

\section{No potential conflict of} interest was reported by the authors.

\section{(C) 2019 Informa UK}

Limited, trading as Taylor \& Francis Group

\section{Tolerance in the Peer Review of Interdisciplinary Research in Architectural Journal Publishing Igea Troiani and Suzanne Ewing}

ABSTRACT In order to consider how to negotiate the publication space of interdisciplinary research in architecture in academic journals, this essay reflects on the current forms of writing in architectural discourse, the history of a "critique militante" architectural (peer) review process within the academy, and the future possibilities of a feminist oriented process that seeks to accommodate otherness. These reflections emerge from our experience as academics and as women editors of the interdisciplinary, multimedia journal, Architecture and Culture, first published in 2013. The essay argues that peer review for interdisciplinary research in architecture needs to be re-negotiated as publishing tolerance through a contingency approach to evaluation. We conclude that academic architectural journal publishing can flourish through broader conversational modes of open, non-hierarchical knowledge exchange and editorial practice where published work undergoes a process of becoming.

\section{Becoming Published}

The process of becoming published can be as much of a black box ${ }^{1}$ to prospective authors as the process of architectural design. 
A generation ago publishing was a domain where the professional press, informed by critical experts, was a lively space of debate, opinion, information and the shaping of public perceptions of what had recently been or was in the process of being built. Scholarly work influential to the architectural discipline, predominantly from an art historical tradition, was cultivated through slower processes of printed books and library circulation, often associated with independent learned societies. While both traditions are still evident today in longstanding titles (Architectural Review, The Architect's Journal, Architectural Association Files and institutionalized publishing houses), academic publishing itself has become a faster, larger, profit-making industry in its own right. Emergent fields of "scientific" architectural research developed in the mid-twentieth century, alongside the expansion of the university sector in the UK and United States. The more recent scaling up, internationalization and marketization of the global higher education sector has contributed to the fueling of e-publishing and the capacity to distribute, access and speedily consume, in real-time, via the internet.

As editors ${ }^{2}$ of an online and print journal, we have asked ourselves over the past six years a series of questions that have been provoked by our activity and experience of constructing the discursive space for an academic journal in the contemporary context. We are participants in the becoming of a space of academic publication, but also an active part of an editorial ecology which has led to around 150 pieces of work becoming published. The ongoing dialogue around these questions inform the positioning and maturing of our collective editorial practice in relation to the journal's aims and scope, articulated at the outset of the first issue. Wider inquiry around the constraints, limits and potentials of academic publication has promoted the exploration and reflection of normative academic formats and practices which we seek to critique and refresh.

In academic publishing, the site and processes of knowledge verification, validity and canonization are primarily led and managed by editors and peer reviewers working within frameworks conditioned by the editorial team, advisory board and publisher. The routines of regular production for an academic journal have exposed dynamics and protocols of academic labor, disciplinary maneuvering and exchanges. As editors reflecting on the production of Architecture and Culture we ask: How can we understand the construction of an academic journal as a space of tolerance for academic knowledge-building? When academic publishing is set up in "disciplinary formations," how do we evaluate interdisciplinary work? Can we understand academic writing with less formal control, classification and static components and still confidently assert and evidence its quality? Can and then how can academic publishing incorporate a practice of tolerance that is unbiased? ${ }^{3}$
Tolerance in the Peer Review of Interdisciplinary Research in Architectural Journal Publishing Igea Troiani and Suzanne Ewing 
"Tolerance lies at the crux of contingencies of context and autonomous production."

Tolerance allows that we are attentive to characteristics of both formal publication and the active space of becoming published. While this can be seen as an almost ubiquitous aspiration (no one wants to see themselves or their work as intolerant), we have found a number of intolerances in the industry of academic publication in architecture, despite active attempts to solicit and invite otherwise. In/tolerances relate to the fixity of academic nomenclature, writing style and tone; the limits of a journal's graphic template/s; the flexibility of peer reviewers to respond to emerging writers and authors for whom English in not their first language; and a predisposition for the expression of peer reviewers' personal judgment over accepting and working with the author's "intention of the work." The tools and techniques of peer review, which are designed to sustain and give validity to a discipline, become complicated and contested when used to approach interdisciplinary work and multimodal formats.

In this article, we examine what is at stake for becoming published. In particular we set out how peer review might be a space of more critical, creative and tolerant (as in enduring) practice between submitted draft and published journal article shared in public. The process of an article becoming published has its own complicated journey: from practice-based author questions grounded in personal experience, to a conference presentation, ${ }^{6}$ to construction of journal submission, to engagement with the dialogue and feedback from one or more academic journal editors and two peer reviewers. Anonymous reviewers and named editors raise issues about focus (better if narrower), fitness for their publishing space, and clarity of purpose and structure all valid criteria in selection for publication. In reviewing this article, one commented, "This paper itself is in a way a bit of an enigma. What is it? Is it a piece of criticism, a review of others work on criticism and review, a piece of research?" Other peer review comments suggested clarity of direction stating "it offers a nascent and necessary response to both calcified academic traditions and to contemporary gender politics"; "The suggestion here is that peer review practices might have some effects on the development and trajectory of a discipline." Reflecting on the exchanges, we notice the varied communicative stances of reviewers - to write in the third person reporting to the managing editor as final arbitrator, or to deliberately speak directly to authors as a mentor might to a student. "Peer" is a complicated responsibility associated with knowledge power relations.

In the end, this published article has changed markedly because of its accumulative iterations that have traversed art and architectural criticism, negative and constructive feedback, disciplinary value-making, and interdisciplinary negotiation. It has not been a smooth or "pure" 
process, and yet with the relational encounters and contingent

adjustments informed by different contextual expectations, the erosions and augmentations of co-writig and over-writing, there has been both a deepening and condensing of our research into into the tolerance of interdisciplinary publication. "Findings" of this intellectual and practical work manifest in the call for papers for this themed journal issue of Architecture and Culture. We are now aware that our motivating intention was to clarify, contextualize and develop our own academic editorial practices, not solely to create a singular academic article output for citation.

What we have learnt from the process of this case of becoming publication at both the scale of editorial practice over six years and in the evolution of this article is the proposition for academic publishing as a space of tolerance: where there is, first, space for disciplinary maneuvering; second, space for hybrid appearance and alteration in academic writing; and third, tolerant practices that value and accommodate emergent and diverse voices and work.

\section{Discursive Formations and the Space for Disciplinary Maneuvering}

In The Archaeology of Knowledge, Michel Foucault defines a process of de-naturalization (removing something or a citizen from its natural setting or nation) through the study of "discursive formations." Foucault considers how knowledge was produced, in particular by an empiricist approach that was embedded within the ideological construction of the "norm." His archaeology of the human sciences demonstrates how "norms" structure and construct discursive fields. Fundamental to Foucault's conception is that a naturalized discourse loses its ideological character and this allows it to appear neutral. But he argues for resistance against this and writes:

these pre-existing forms of continuity, all these syntheses that are accepted without question, must remain in suspense. They must not be rejected definitely of course, [...] we must show that they do not come about by themselves, but are always the result of a construction of the rules of which must be known. ${ }^{8}$

Architectural academic publications manifest institutionalized disciplinary formations. They are disciplined into categorized fields associated with comparative metrics, and with reinforcing cultures of scope, selection, inclusion and exclusion. ${ }^{9}$ Constructing a new space of publication requires a clear rationale that defines a new territory and is acknowledged in context. This sets up an academic publishing industry which stabilizes the understood center of disciplines. Academic hierarchies and bias can be inbuilt where there is a process of peer review that is not fully anonymized or "double blind." 10 Academic fields also carry into the peer review process the disciplinary cultures of
Tolerance in the Peer Review of Interdisciplinary Research in Architectural Journal Publishing Igea Troiani and Suzanne Ewing 
interpretation of intention, judgment of quality and a recognizable knowledge. In architecture this culture is informed by the culture of the architectural critic.

For scholar Joseph Rykwert, the task of the reviewer or critic is to create an architectural hierarchy of excellence in the field. He argues that:

the business of a critic is to discriminate the better from the worse, or - if you like - the more beautiful from the uglier, the more valuable from the less. The word implies it. In ancient Greek, it pertains to winnowing or sieving; separating the wheat from the chaff. ${ }^{11}$

Architectural critics in magazines are sifters and interpreters of architectural knowledge who make distinctions for a professional audience. $^{12}$ The critic's project is to produce criticism - design reportage or journalism - with "instrumental purpose."13 Architectural criticism validates and invalidates. It gives value or not to buildings, designers and their design philosophies. As Peter Collins notes, architectural "criticism [... does] not simply mean the omission of buildings thought to deserve censure, but positive statements of a point of view, both for and against." ${ }^{14}$ This is done through the hierarchical valuing of select criteria which have evolved from the first century BC.

Criteria for evaluating excellence in architecture has been traced from Vitruvius' conceptions of "strength [...] utility [...] and grace" to Leon Battista Alberti's (1450) concepts: "appropriate to its use, lasting in structure, and graceful and pleasing in appearance," to Sir Henry Wotton's (1624) three conditions of "commodity, firmness and delight." ${ }^{15}$ As William $H$. Hayes argues, ${ }^{16}$ the criticism of buildings has "insecurely wavered" in architectural treatises over history around these criteria. Historically institutionalized criteria generally form a framework for criticism of architectural design in education and in the professional press and are pursued more or less diligently.

The benefit of architectural criticism is not only the separation of the good from the bad but also that it can teach the bad lessons for improvement. As Naomi Stead writes, "A good critic can teach the (artist, architecture student or) architect things about their own (artwork, not built design or) building, things which they haven't realized, haven't noticed, and even, significantly, haven't intended"17 and locate the work under consideration within a historical context of current and future disciplinary production. ${ }^{18}$ The social framework for the delivery of that criticism in the studio, in which students learn the skills to criticize their own work and that of others, has historically been delivered in an authoritarian tone. A history of destructive, pedagogically combative criticism in the architectural studio has tended to focus on "fault-finding" rather than "discernment." ${ }^{19}$ As a consequence, design review criticism in 
the British architectural press for instance was "frequently a playground for the display of intellectual superiority, arrogance and occasional bullying." ${ }^{20}$ But in the late 1980s, around the time of the emergence of feminist critique in architectural theory, the established masculinist image of the architecture critic who is a militant "fighter" or "critique militante" engaged in a battle over architectural value began to be questioned. ${ }^{21}$

According to Stead, "there is a pervasive belief abroad that criticism is only ever rigorous and true if it is negative." 22 In cases of "critique militante," the architect being punished can sometimes relish the negative commentary on the work on the basis that it was delivered in the spirit of "affectionate concern expressed in a stern or unsentimental manner (as through discipline) especially to promote responsible behavior." ${ }^{23}$ A consequence of "a curious masochism," the "common belief [in architecture is] that even the most insightful and incisive criticism does not count as adequately "critical" if it comes to an ultimately positive conclusion." 24 Often, "enthusiasm or praise is read as a sign of naivety or weakness on the part of the critic." 25

Stead observes that nowadays criticism is no longer about "taking prisoners." ${ }^{26}$ Nor is it solely the domain of establishment critics who are predominantly "white, male and old." 27 Vanessa Quirk explains: "The Architecture Critic is Dead!' But you know what? Good riddance. Because criticism hasn't died the way you think. It's just been changed beyond recognition. And frankly, for the better." 28 Outsider critics inside architecture can disturb architecture's "discursive formations" because their outsider status does not oblige them to the rules of the architectural community. It is this approach of bringing outside expertise from experts in interrelated disciplines to architecture and more diverse gender, race, ethic and class backgrounds that has been implemented into the peer review process of academic architectural publishing in Architecture and Culture.

In order to accommodate the difference associated with interdisciplinary review, the standard peer review process had to be redefined. These changes have endeavored to present a more tolerant space of readership but have themselves been complicated by normative bias in disciplines outside architecture. The suggestion by philosopher Julia Kristeva ${ }^{29}$ that experts in a discipline should not be hesitant to collaborate and converse with one another suggests that disciplinary boundaries need not be defended but instead understood, absorbed and transgressed. This is challenging, and requires intellectual work, not just "polite filtering." ${ }^{30}$ The architectural "artistic scholar" shifts from being an isolated authority working solely within their academic community in a hierarchical, institutionally prescribed manner to an academic who engages with art practices (in other visual arts) in broader interdisciplinary knowledge teams. Through a more open, inclusive, lessguarded practice, the "commonly understood social norms" 31 in a field,
Tolerance in the Peer Review of Interdisciplinary Research in Architectural Journal Publishing Igea Troiani and Suzanne Ewing 
which establish levels and thresholds of value and quality, are likely to evolve and expand slowly for potential transformation of both the object or subject being researched and the agency of peer review. The peer reviewer shifts from being an expert arbiter of quality and value within fixed disciplinary scope to an interdependent practitioner sifting judgments in between disciplines.

Through our involvement in the production of Architecture and Culture, we have undertaken research on the standard peer review process for assessing interdisciplinary research in architecture. Openness to the contemporary "craft" of interdisciplinary research in architecture means working well with words: text, language and syntax; but also with other visual and digital media; and with expertise in transdisciplinary understanding and communication. Interactive digital architectural scholarship may work with new methods and this has significant consequences for the tools of "writing" and evaluation through readership and viewership. Orality and visuality become new research tools and the audio and visual recordings become a new syntax in architectural publishing. $^{32}$

Open assessment of interdisciplinary research requires an empathetic gaze toward inclusive practice and understanding across disciplines. Operating at the edges of disciplines and attending to the "intention of the work," 33 it calls for tactical, sometimes partisan, dialogue, selection and crafting. As editors we work towards a position of situated editorial practice that encompasses all sensorial layers considered in relation to their political positioning. We actively try to resist creating autonomous textual, audio and visual components of publication, with associated hierarchies of importance. We support the contestation of the disciplinary limits and normalizations historically imposed upon architectural publication. This does not mean that quality of research is diminished because originality, significance and rigor of practice in between disciplines remain the paramount criteria of evaluation. What is sacrificed is the "appearance" in which architectural publishing can manifest. What is gained is the creation of a publishing space for collaborative exchange and dialogue rather than one of intellectual combat or dismissiveness. Iterative artistic processes of research are supported for their rigor and modes of enquiry and not judged hierarchically in a quantitative/qualitative battle of superiority, or one between practice/theory. Rather than read this as a crisis of critical confidence we argue that tolerance in the peer review process of interdisciplinary research in architecture offers a sustainable, intellectually and sensorial enrichment to architectural knowledge and its exchange inside and outside the discipline.

Authors, peer reviewers and editors of interdisciplinary architectural research have a combined role which includes selection of quality work, setting thresholds and consideration of the revisions. To achieve this, editors need to trust critics to be open, and to encourage 
transparent evaluation criteria. The invitation by Hayes ${ }^{34}$ to be "radically empirical" through stages of discursive negotiation, rating and cultivation of "good balanced mixtures" requires a collective practicing or enactment of peer review towards original, significant and rigorous interdisciplinary research publication. There are clues perhaps also in Banham's ${ }^{35}$ move towards what he terms a "situationist criticism" where knowledge of decision-making histories are as vital to radical evaluation as qualitative evaluation of the completed project.

A rigid peer review system that is unable to negotiate, recognize and support interdisciplinary architectural scholarship can be a barrier to the possible creative and innovative exchange between new media technologies and traditional academic writing and between disciplines. Interdisciplinary architectural peer reviewers acting with tolerance must be selected carefully. Dialogue between peer reviewers, editors and authors can be cultivated towards reflective and mastered practices within a critical team. This involves un-gendering, un-acculturating (in disciplinary terms) and hybridizing the architectural writer, peer reviewer and editor. Informed by a more positive culture of architectural criticism, re-tooling the instruments and tactics of peer review enables space for disciplinary maneuvering.

\section{Space for Hybrid Forms and Appearance of Architectural "Writing"}

Ways of "making public" discourse on architecture and buildings today is through written or spoken words that are illustrated and published in print and/or electronic format. The widespread use of computers since the 1970s has accelerated knowledge exchange and with it created new electronic formats or ways of writing, reading, seeing and reading architectural publication. Arguably newspapers, coffee table style magazines and books, blogs and videos in the popular press offer a lighter form of discourse than academic journals, manuscripts and documentaries that publish scholarly discourse. While architectural journalists and academic writers might deal with the same subject matter, such as a particular building or architect, the tone of commentary and style of writing can vary vastly with regards to who their audience is and what the audience expectations and standards are in that particular type of publication. The journalist who writes for a wider public or an everyday practitioner audience is very different from the architectural academic who writes for a select and niche academic audience of researchers/scholars. The aims and methods, style and form of prose writing/voice and speed of production and dissemination vary greatly, in part due to the degree to which the work is scrutinized or not before publication.

In addition to different types of architectural publications offering alternative platforms for diverse voices and exchanges, different forms of architectural writing offer a variety of different author freedoms. For instance, building reviews in architecture magazines and online, are often
Tolerance in the Peer Review of Interdisciplinary Research in Architectural Journal Publishing Igea Troiani and Suzanne Ewing 
written using reader-friendly language and are pithier, assuming that practicing architects prefer to read simpler and shorter pieces of prose that are heavily illustrated - fewer words, more images. Traditional scholarly journal articles that build on existing literature in their field of knowledge are typically substantive, lengthy 7000-10,000-word written articles evidenced by originally generated research data and/or illustration that have had a long gestation period. Academic scholarship usually employs a "high-brow" and learned language citing discipline specific scholars that are not always familiar to the greater public. The subject matter of conventional academic scholarship is sometimes incomprehensible, irrelevant or impractical, or too wordy for the public or everyday architectural practitioner.

Then there is the additional issue of the academic architectural researcher who wants to explore territory beyond the limits of their discipline as "artist scholar" 36 and/or as literary scholar. These can include the design research of practicing architects or the work of academic researchers within the university who undertake their research practice using the modes conventional to another discipline, for example, creative writing, installation art, filmmaking etc. Architectural researchers who want to go beyond the limits of the written page to explore creative, interdisciplinary academic scholarship produce experimental prose, poetry, art-house films, visual essays, visual artwork - captioned or not, sound recordings etc. or a mixture of these as architectural research.

While select established academics - such as Jennifer Bloomer, Jane Rendell and Hélène Frichot - have been writing in alternative ways to the third person, impersonal preferred convention of academic prose and have successfully influenced the limits of what is written about in architecture and the mode and tone of voice, the academic publishing arena for academics remains stubbornly limited in its definition of what is worth publishing and what is not. Even though modes of research and communication have evolved, the process of filtering, censoring and editing the knowledge disseminated in architectural academic publication remains surprisingly static. The disciplining of "discursive formations" is implicitly delegated to the labor of peer reviewers and editors.

In The Future of the Image, ${ }^{37}$ Jacques Rancière sets out to analyze the visual arts of painting, cinema and audiovisual installations as "images," and their connections to a narrative or affective end occupy center stage. ${ }^{38}$ Rancière concludes that unlike naked images, still or moving artistic images "are [...] operations: relations between a whole and parts; between a visibility and a power of signification." 39 When an artistic technique is used to create images, multimedia or mixed media, a series of layered exchanges occurs between the image, its resemblance and hyper-resemblance. ${ }^{40}$ It is the "regime of 'imageness,' a particular $[\ldots]$ articulation between the visible and the sayable" that allows a double poetics to occur, "impervious to any narrativization, any intersection of meaning." ${ }^{41}$ According to Rancière it is through the 
interchange and blurring between mental and material realities that the regime of images enables discursive practices to be materially embedded and to emancipate spectators as artists to construct knowledge and readings in their own terms. In this now broader sensorial "page"/screen of architectural publishing, the work undergoes continuous re-reading and re-evaluation.

Visual architectural review does exist ${ }^{42}$ but is rarely scrutinized. Inverting Niedderer and Roworth-Stokes' three categories of objectivity, reliability and validity - into subjectivity, unreliability and lack of validity can have negative connotations in an academic scientific context and can problematize the review of artistically or audio and visually generated scholarship. ${ }^{43}$ Questions are raised about the appropriateness of language, medium and format and clarity versus ambiguity of argument. ${ }^{44}$ Close reading of the wider literature on peer review standards reveals, however, that while the need to present a "truth" is explicit, there is also a need for the best research to offer insight, opinion, "belief" and "care." 45 The truth of fiction ${ }^{46}$ is also in tension with the truth of non-fiction.

\section{Emergent Publishing: From the Standard Peer Review Process to a Contingency Approach}

The fairly standard-across-all-disciplines peer review assessment criteria for academic publishing that we still use today were broadly defined "in 1731 by the Royal Society of Edinburgh to ensure the maintenance of intellectual standards and objectivity." 47 These rigorous rules of what constitutes "appropriate" works of research exist for every discipline and are determined within their hierarchically structured institutional "discursive formations." In general, they are all based on the standard criteria of originality, significance and rigor. ${ }^{48}$

The issue of making an original contribution of new knowledge is paramount for both emerging and established scholars in academic architectural research and publishing. To locate new contribution, the author(s) need/s to justify how their knowledge is ground-breaking by correctly citing its difference within the existing field, and naming others who are working close by but not on their precise topic. Locating the significance of research is achieved through correct citation, clarity of writing and substantiation of argument. Rigor of methods used and the methods of disseminating research outcomes is fundamental to substantiate deep research that is meaningful, efficacious and that can be proven repeatedly.

Unlike architectural newspaper columns or architectural magazines or blogs that go through a light or no process of prepublication filtering, censorship and editing and where the author's writing is not tampered with, in terms of its commentary, at all or substantially, in the academic publishing arena a rigorous, double-blind, peer review process by external expert reviewers and editors in the field is the touchstone for ensuring high publication quality and standards.
Tolerance in the Peer Review of Interdisciplinary Research in Architectural Journal Publishing Igea Troiani and Suzanne Ewing 
The process of being able to accept, or accept with minor or major modification, or reject a submission outright based on the assessment criteria, allows editors to choose and shape material for each journal issue. In the decision for minor or major changes, editors are able to ask the author to modify their submission based on the suggestions of the expert reviewers.

Understanding how to "know" how to separate "the wheat from the chaff" 49 occurs typically through a university education in architecture where one learns "an inspecting gaze." According to Foucault, "an inspecting gaze" within institutions carried within scholarly communities and "developed in the modern era" is able to exercise "power [... ] continuously." 50 Training within institutional frameworks allows researchers to practice self-surveillance so that institutional power only need be exerted softly. Knowing and understanding the limits of "making public" is fundamental to the practice of architectural knowledge production. While institutional training teaches peer review standards, often peer reviewers misunderstand the terms through which the work is being presented. For instance, Ellison ${ }^{51}$ observes the tendency towards the lengthening and reshaping of refereed work in the field of economics since the 1960s where the rigor rather than the originality of work is what tends to be reviewed. Whether understood or misunderstood, quality journal publication is affirmed through the hierarchy of the power relation between the author and reviewer, which can be a pre-existing relationship or a non-existent one.

In academic publishing, authors are offered the opportunity through the publisher's online submission platform system to nominate reviewers. Journal editors are entitled to choose from that list or find others. This depends on the proximity of the reviewer to the production of the research but also on the network of reviewers available to the editor. This is an important space of tolerance, because the nominated reviewer could, arguably, be assumed to cast a more favorable eye over a submission than a non-nominated peer reviewer. Still, whether a peer reviewer is tolerant or intolerant of a submission does not always correlate with personally "knowing" the author's work or not. Universitydriven publication uses a peer review process that presents itself as a neutral space in which a learned, tempered and balanced review of the work takes place.

In order to retain maximum objectivity, the peer review process is compulsorily blind so that the author is never made aware of their peer reviewer's identity; nor are the reviewers aware of the author's identity. The words of the peer reviewer are shared only with the editor(s). Unlike the studio critique where there is a face-to-face dialogue between the (assumed less knowledgeable) student and the (more knowledgeable) tutor-critics who are present and accountable for their actions, or in magazine publishing where architect and critic are openly known to one another, the anonymity of the peer reviewer allows them certain 
privileges. Owing to the lack of personal accountability to the author whose work is under peer review, these privileges relate to the depth, type and tone in which the peer reviewer's feedback is delivered. As such they can present their reading of the work they are assessing in a space between constructive and unconstructive criticism, the latter aligning with Rykwert's "critique militante." There is general consensus that there is a space of tolerance associated with the peer reviewer chosen that can impact on the decision to publish. Being too skilled or not skilled enough, having "critical distance" or not, means that there does not always exist an effective method to agree on the quality of an academic publication within one discipline's discourse. Peer reviewers, like studio critics or architectural journalists, can often totally disagree or each bring up different issues for the author to attend to. Very few submissions are accepted unconditionally by both peer reviewers. ${ }^{52}$ So while there are many different types of peer review within all disciplines, such as masked, open and informal, ${ }^{53}$ there is consensus that peer review is not entirely unbiased by the expert knowledge of the reviewer. ${ }^{54}$ Peer review has an institutional and instrumental history that is complex, content biased (scientific versus humanities), driven by social academic networks, and, as Sandra Kaji-O'Grady notes, gendered. ${ }^{55}$

The standard peer review criteria and process that remain in use were created around two centuries before the emergence of new digital technologies which, as has already been stated, has affected the kinds of submissions researchers are able to produce and the degree to which their research goes beyond the boundaries of their disciplinary knowledge. There is also the issue of university research becoming tied, under systems of neoliberal governance, to the need for independent income generation within universities: a growing trend seen for instance in discussions of implementing Plan S - an open-access science model of funded publishing launched in Europe in 2018. As Wendy Brown writes, "The move to judge every academic endeavor by its uptake in nonacademic venues (commerce, state agencies, NGOs [nongovernmental organizations]), as the British Research Excellence Framework (REF) does, is equally damaging [ ... because] these metrics abjure humanistic enquiry [...]." ${ }^{56}$ When research outputs become equated to income generation or the work that is published requires funding, the flexibility and tolerance in quality of academic publication is arguably limited and compromised. The "academic capitalism" 57 imperative steering most architecture schools nowadays has created biases in relation to the support of scientific research versus research in the humanities in architecture.

Nowadays academics are encouraged to undertake research that is seen to affect or have an impact upon society, the economy and industry. Overall, research in the sciences and humanities is increasingly performance assessed in terms of its impact on the wider world economically and globally. Now, academics are arguably in a mode of production rather than intellectual exploration and contemplation. Many
Tolerance in the Peer Review of Interdisciplinary Research in Architectural Journal Publishing Igea Troiani and Suzanne Ewing 
universities require academic university "outputs" - as publication has been renamed in many countries - to be more conventional and less unconventional. While the UK REF 2014 encouraged and assessed what appeared to be an open and democratic range of submissions, some output types were submitted in far greater numbers than others. For instance, in the Subpanel 16: Architecture, Built Environment and Planning, an overwhelming 157,021 double-blind refereed journal articles where assessed in contrast to 28,628 (parts of) books, 757 physical artifacts, 1746 exhibitions and performances, and 761 digital artifacts including databases. ${ }^{58}$ Shorter than writing a book manuscript, but considered equally "REF returnable," peer review journal articles, because of their process of faster production than a manuscript, can offer maximum financial remuneration to universities for a greater economy of words. This has meant that many researchers feel pressured into selfdisciplining to this format therefore limiting what they produce as research. The aim of Architecture and Culture is to actively resist this trend and to encourage exploratory research.

To assess interdisciplinary architectural research, we propose a contingency approach as a more tolerant mode of peer review. Barbara Herrnstein Smith argues for a contingency approach to the valuation of literature through an anti-essentialist understanding. She discusses the common assumption amongst literary critics that there are particular works of art or literature, such as William Shakespeare's sonnets, which are of absolute value. ${ }^{59}$ But she contests the notion of the absolute value of any "great" literary work, and the failure of anyone to see that value as a sign of mental ignorance on the basis that literary value is the product of a continued process of cultural circulation contingent on preevaluations. Smith does not see value as fixed. How something comes to be valued requires looking, not solely at the subject, but through investigating the pre-evaluations and re-evaluations of that work by the various agents assessing it.

Architecture and Culture uses a contingency approach to the valuation of interdisciplinary research submitted. As co-editors with Diana Periton and Jessica Kelly and book editor Stephen Walker, we define the aim of the journal as to publish exploratory research that is artistic, rigorously speculative, visually and verbally stimulating. ${ }^{60}$ Architecture and Culture is directed at multidisciplinary practitioners as well as theoretical, scholarly audiences including architects, artists and urban designers, filmmakers, animators and poets, historians, geographers, anthropologists and other social scientists. It aims to promote a genuine interdisciplinary textual and audiovisual conversation "about what architecture might be and what it can do." 61 As architecturally trained writers broaden their knowledge of and modes of practice learned from other disciplines, and non-architecturally trained writers broaden their knowledge of architecture, it has become possible to reconsider what is better, beautiful, more valuable for architecture in 
relation to other disciplines, and as renewed interdisciplinary endeavor in architectural research. This position builds on the writings of other philosophical and political thinkers about open and friendly knowledge exchange within and beyond the university.

Igea Troiani (PhD) is an architect, academic and independent filmmaker who has worked in Australia, Germany, the UK and China. She is currently a Professor of Architecture at Xi-an Jiaotong-Liverpool University in Suzhou. Her portfolio of research is based in three areas: (1) the social production of architecture; (2) architecture, neoliberalism and labor; and (3) architecture and media. In addition to her written publications, she produces theory as film; since 2004, she has made films on the politics of architectural production, most recently under her production company Caryatid Films. She is a founder of Original Field of Architecture (Oxford, UK) with Andrew Dawson, founder and editor-in-chief of Architecture and Culture, co-editor of The Politics of Making (2007) and Transdisciplinary Urbanism and Culture (2017).

Suzanne Ewing is an architect, academic and educator and was Head of the Edinburgh School of Architecture and Landscape Architecture at the University of Edinburgh, 2016-18. She co-founded ZONE architects, UK, in 2002. Underpinning the inquiry of her critical design work in sited architecture projects and the speculative domain of design studios in education, is elucidating and nuancing theories, skills, judgments and potentials embedded in practice-based methodologies, which traverse aesthetics and ethics: knowing how to practice, knowing how to construct a good project. Publications include Architecture and Field/Work (Routledge, 2011), and articles in Journal of Architecture, Architectural Theory Review, NORDIC and Charette. She is co-editor of the international award-winning journal Architecture and Culture.

\section{Notes}

1 Jane Jacobs, Ada-Louise Huxable and Reyner Banham, for instance, used their positions as "outsider" critics to contest the discipline's discourse as a secret "black box"; Reyner Banham, "A Black Box, The Secret Profession of Architecture," in A Critic Writes: Selected Essays by Reyner Banham, (Berkeley, Los Angeles and London: University of California Press, 1999), 292-9.

2 The authors are both steering group members of the international, interdisciplinary humanities research network, Architectural History Research
Tolerance in the Peer Review of Interdisciplinary Research in Architectural Journal Publishing

Igea Troiani and Suzanne Ewing
Association (AHRA) based in the UK. As an Executive Committee member of the Society of Architectural Historians, Australia and New Zealand (SAHANZ), 2003-05, Troiani was involved in reformatting its journal, Fabrications. After moving to the UK, she joined the AHRA in 2006. Ewing joined AHRA in 2008. From 2009 to 2012, Troiani was chair of the organization and in that role initiated the formation of Architecture and Culture for which both authors are editors. Through the AHRA and their own interdisciplinary research practice, the 
authors understand that some academics in architectural history and theory today want to use their designed skills to work in alternative creative writing and graphic ways to produce publications that employ design and personal artistic expression.

3 Sandra Kaji-O'Grady, "Gender and Anonymous Peer Review," in Architecture and Feminisms: Ecologies, Economies, Technologies, ed. Hélène Frichot, Catharina Gabrielsson, and Helen Runting (London: Routledge, 2018), 132-137.

4 Genevieve Baudoin, "A Matter of Tolerance," The Plan Journal (2016), available online: http://www. theplanjournal.com/article/mattertolerance (accessed February 2, 2019).

5 Justine Clark and Paul Walker, "Negotiating the Intention of the Work," Volume, 36 [special issue "Ways to Be Critical"] (2013): 24-29.

6 Igea Troiani and Suzanne Ewing, "New Architectural Criticism: How to Separate the Wheat from the Chaff," in Proceedings for The European Academy of Design (EAD 11) Conference, Paris Descartes University, Paris, and College of Arts, Paris \& Boulogne sur Seine, France, 22-24 April 2015.

7 Michel Foucault, The Archaeology of Knowledge, ed. A. Sheridan (London: Tavistock, 1972), 47-49.

8 lbid., 25.

9 For instance terminologies related to the different roles practice(s) can take in Art and Design research are explored in $\mathrm{K}$. Niedderer and S. Roworth-Stokes (2007), 4-9.

10 Kaji-O'Grady, “Gender and Anonymous Peer Review."

11 Joseph Rykwert, "Does Architecture Criticism Matter?," Domus 979 (April 2014): 4.

12 Peter Collins, Architectural Judgement. (London: Faber \& Faber, 1971).

13 Naomi Stead, "Three Complaints about Architectural Criticism," Architecture Australia 92, no. 6 (2003): 50.

14 Peter Collins, "The Interrelated Roles of History, Theory, and Criticism in the Process of Architectural Design," The History, Theory and Criticism of Architecture (1965): 6.
15 William H. Hayes, "Architectural Criticism," Journal of Aesthetics and Art Criticism 60, no. 4 (2002): 325.

16 Ibid.

17 Stead, "Three Complaints about Architectural Criticism," 52.

18 James Elkins and Matthew Engelke, What Happened to Art Criticism? (Chicago, IL: Prickly Paradigm, 2003), 8.

19 Stead, "Three Complaints about Architectural Criticism," 50.

20 Momen El-Husseiny, review of "The Crit: An Architecture Student's Handbook Rosie Parnell and Rachel Sara," Journal of Architectural Education 62, no. 3 (2009): 91.

21 Rykwert, "Does Architecture Criticism Matter?," 4.

22 Stead, "Three Complaints about Architectural Criticism," 50.

23 See https://www.merriam-webster.com/ dictionary/tough\%20love (accessed February 2, 2019).

24 Stead, "Three Complaints about Architectural Criticism," 50.

25 Ibid.

26 Ibid.

27 Benjamin Forgey, "White, Male, Old," Arkkitehti 100, no. 3 (2003): 95.

28 Vanessa Quirk, "The Architect Critic is Dead (Just Not for the Reason You Think)," Archdaily (April 2012), available online: https://www.archdaily.com/ 223714/the-architect-critic-is-dead-justnot-for-the-reason-you-think/.

29 Julia Kristeva, "Institutional Interdisciplinarity in Theory and Practice: An Interview," in De-, Dis-, Ex, Volume Two: The Anxiety of Interdsiciplinarity, ed. Alex Coles and Alexia Defert (London: Black Dog, 1997), 6.

30 Richard Coyne, "Even More than Architecture," in Design Research in Architecture: An Overview, ed. Murray Fraser (Aldershot: Ashgate, 2013), 201.

31 Glenn Ellison, "Evolving Standards for Academic Publishing: A q $r$ Theory," Journal of Political Economy 110, no. 5 (2002): 994-1034.

32 Gillian Rose, Visual Methodologies: An Introduction to Researching with Visual Materials, 3rd ed. (London: Sage, 2012).

33 Clark and Walker, "Negotiating the Intention of the Work."

34 Hayes, "Architectural Criticism," 329. 
35 Reyner Banham, "Convenient Benches and Handy Hooks: Functional Considerations in the Criticism of the Art of Architecture," The History, Theory and Criticism of Architecture (1964): 103.

36 James G. Daichendt, Artist Scholar: Reflections on Writing and Research (Bristol: Intellect, 2011).

37 Jacques Rancière, The Future of the Image. trans. G. Elliot (London: Verso, 2007).

38 G. Mecchia, "The Future of the Image" [Review], Symplokē 16, nos. 1-2 (2008): 313-316.

39 Rancière, Future of the Image, 3.

40 Ibid., 8.

41 Ibid., 11.

42 David Wild, "OP Arch," Journal of Architectural Education 62, no. 3 (2009): 2-32, 94.

43 Niedderer and Roworth-Stokes, "The Role and Use of Creative Practice in Research and its Contribution to Knowledge" (paper presented at the IASDR International Conference, 2007).

44 J. J. Charlesworth, "Features: The Dysfunction of Criticism," Art Monthly (Archive: 1976-2005), no. 269 (2003): 1.

45 Elizabeth Wager, Fiona Godlee and Tom Jefferson. How to Survive Peer Review (London: BMJ Books, 2002), 15.

46 Colomina, cited in Beatriz Colomina, Gabriele Mastrigli, Matthew Stadler and Kestrel Rattenbury, "4 Statements," Volume no. 1 (2005): 75.

47 Kaji-O'Grady, "Gender and Anonymous Peer Review," 133.

48 These criteria were used in the UK's Research Excellence Framework (REF) 2014.

49 Rykwert, "Does Architecture Criticism Matter?"

50 Michel Foucault, "The Eye of Power," in Power/Knowledge: Selected Interviews and Other Writings, 1972-1977, ed. C. Gordon (New York: Pantheon, 1980), 151.
51 Ellison, "Evolving Standards for Academic Publishing," 995.

52 Wager et al., How to Survive Peer Review, 28; Ellison, "Evolving Standards for Academic Publishing ," 995.

53 Wager et al., How to Survive Peer Review, 12.

54 Ellison, "Evolving Standards for Academic Publishing;" Wager et al., How to Survive Peer Review; Suzanne Ewing, Jeremie M. McGowan, Chris Speed and Victoria C. Bernie, eds., "Field/Work and Site," in Architecture and Field/Work (Abingdon and New York: Routledge, 2010); Coyne, "Even More than Architecture."

55 Kaji-O'Grady, "Gender and Anonymous Peer Review."

56 Wendy Brown, Undoing the Demos: Neoliberalism's Stealth Revolution (Cambridge, MA: MIT Press, 2015), 196.

57 Igea Troiani, "Academic Capitalism in Architecture Schools: A Feminist Critique of Employability, 24/7 Work and Entrepreneurship," in Architecture and Feminisms: Ecologies, Economies, Technologies, ed. Hélène Frichot, Catharina Gabrielsson and Helen Runting (London: Routledge, 2017), 170-180.

58 Research Excellence Framework, Panel Criteria and Working Methods REF01.2012 (2012), 64 "Output Types"; 5700 submissions were double-weighted.

59 Barbara H. Smith, Contingencies of Value: Alternative Perspectives for Critical Theory (Cambridge, MA: Harvard University Press, 1988), 36.

60 Igea Troiani and Suzanne Ewing, "Inside Architecture from the Outside: Architecture's Disciplinary Practices," Architecture and Culture 2, no. 2 (2014): 151-166.

61 See http://www.tandfonline.com/action/ journallnformation?show=aimsScope \&journalCode=rfac20 (accessed February 2, 2019).

\section{8}

Tolerance in the Peer Review of Interdisciplinary Research in Architectural Journal Publishing

Igea Troiani and Suzanne Ewing

\section{References}

- Banham, Reyner. 1999. "A Black Box, The Secret Profession of Architecture." In A Critic Writes: Selected Essays by Reyner Banham, 292-299. Berkeley, Los Angeles and London: University of California Press.
- Banham, Reyner. 1964. "Convenient Benches and Handy Hooks: Functional Considerations in the Criticism of the Art of Architecture." In The History, Theory and Criticism of Architecture: Papers from the 
1964 AIA-ACSA Teacher Seminar, edited by Marcus Whiffen, 91-105. Cambridge, MA: MIT Press.

- Baudoin, Genevieve. 2016. "A Matter of Tolerance." The Plan Journal: 33-46. Available online: http://theplanjournal.com/ system/files/articles/TPJO_0_4_Art_Prof_ Genevieve_Baudoin_1.pdf.

- Brown, Wendy. 2015. Undoing the Demos: Neoliberalism's Stealth Revolution. Cambridge, MA: MIT Press.

- Charlesworth, J. J. 2003. "Features: The Dysfunction of Criticism." Art Monthly (Archive: 1976-2005), September, no. 269: 1.

- Clark, Justine, and Paul Walker. 2013. "Negotiating the Intention of the Work." Volume, 36 [special issue "Ways to Be Critical"]: 24-29.

- Collins, Peter. 1971. Architectural Judgement. London: Faber \& Faber.

- Collins, Peter. 1965. "The Interrelated Roles of History, Theory, and Criticism in the Process of Architectural Design." In The History, Theory and Criticism of Architecture: Papers from the 1964 AlAACSA Teacher Seminar, edited by Marcus Whiffen, 1-9. Cambridge, MA: MIT Press.

- Colomina, Beatriz, Gabriele Mastrigli, Matthew Stadler, and Kestrel Rattenbury. 2005. "4 Statements," Volume, no. 1: 74-79.

- Coyne, Richard. 2013. "Even More than Architecture." In Design Research in Architecture: An Overview, edited by Murray Fraser, 185-204. Aldershot: Ashgate.

- Daichendt, James G. 2011. Artist Scholar: Reflections on Writing and Research. Bristol: Intellect.

- El-Husseiny, Momen. 2009. Review of "The Crit: An Architecture Student's Handbook Rosie Parnell and Rachel Sara." Journal of Architectural Education, 62, no. 3 (2009): 90-92.

- Elkins, James, and Matthew Engelke. 2003. What Happened to Art Criticism? Chicago, IL: Prickly Paradigm.

- Ellison, Glenn. 2002. "Evolving Standards for Academic Publishing: A q $r$ Theory." Journal of Political Economy, 110, no. 5: 994-1034.

- Ewing, Suzanne, Jeremie M. McGowan, Chris Speed, and Victoria C. Bernie, eds. 2010. "Field/Work and Site." In
Architecture and Field/Work. Abingdon and New York: Routledge.

- Forgey, Benjamin. 2003. "White, Male, Old." Arkkitehti 100, no. 3: 95.

- Foucault, Michel. 1972. The Archaeology of Knowledge, edited by A. Sheridan. London: Tavistock.

- Foucault, Michel. 1980. "The Eye of Power." In Power/Knowledge: Selected Interviews and Other Writings, 1972-1977, edited by C. Gordon. New York: Pantheon.

- Hayes, William H. 2002. "Architectural Criticism." Journal of Aesthetics and Art Criticism, 60, no. 4: 325-329.

- Kaji-O'Grady, Sandra. 2018. "Gender and Anonymous Peer Review." in Architecture and Feminisms: Ecologies, Economies, Technologies, edited by Hélène Frichot, Catharina Gabrielsson, and Helen Runting, 132-137. London: Routledge.

- Kristeva, Julia. 1997. "Institutional Interdisciplinarity in Theory and Practice: An Interview." In De-, Dis-, Ex, Volume Two: The Anxiety of Interdsiciplinarity, edited by Alex Coles and Alexia Defert, 1-22. London: Black Dog..

- Mecchia, G. 2008. "The Future of the Image” [Review]. Symplokē, 16, nos. 1-2: 313-316.

- Niedderer, K., and S. Roworth-Stokes. 2007. "The Role and Use of Creative Practice in Research and its Contribution to Knowledge." Paper presented at the IASDR International Conference.

- Quirk, Vanessa. April 2012. "The Architect Critic is Dead (Just Not for the Reason You Think)." Archdaily. Available online: https:// www.archdaily.com/223714/the-architectcritic-is-dead-just-not-for-the-reasonyou-think/.

- Rancière, Jacques. 2007. The Future of the Image, translated by G. Elliot. London: Verso.

- Research Excellence Framework. 2012. Panel Criteria and Working Methods REF01.2012.

- Rose, Gillian. 2012. Visual Methodologies: An Introduction to Researching with Visual Materials, 3rd ed. London: Sage.

- Rykwert, Joseph. 2014. "Does Architecture Criticism Matter?" Domus 979, April: 4.

- Smith, Barbara H. 1988. Contingencies of Value: Alternative Perspectives for Critical Theory. Cambridge, MA: Harvard University Press. 
- Stead, Naomi. 2003. "Three Complaints about Architectural Criticism." Architecture Australia, 92, no. 6: 50-52.

- Troiani, Igea. 2017. “Academic Capitalism in Architecture Schools: A Feminist Critique of Employability, 24/7 Work and Entrepreneurship." In Architecture and Feminisms: Ecologies, Economies,

Technologies, edited by Hélène Frichot, Catharina Gabrielsson and Helen Runting. 170-180. London: Routledge.

- Troiani, Igea, and Suzanne Ewing. 2014. "Inside Architecture from the Outside: Architecture's Disciplinary Practices." Architecture and Culture, 2, no. 2: 151-166.
- Troiani, Igea, and Suzanne Ewing. 2015. "New Architectural Criticism: How to Separate the Wheat from the Chaff." In Proceedings of The European Academy of Design (EAD 11) Conference, Paris Descartes University, Paris, and College of Arts, Paris \& Boulogne sur Seine, France, 22-24 April 2015.

- Wager, Elizabeth, Fiona Godlee, and Tom Jefferson. 2002. How to Survive Peer Review. London: BMJ Books.

- Wild, David. 2009. "OP Arch." Journal of Architectural Education, 62, no. 3: 2-32, 94.
30

Tolerance in the Peer Review of Interdisciplinary Research in Architectural Journal Publishing

Igea Troiani and Suzanne Ewing 